\section{5-FU multifocal inflammatory leukoencephalopathy and dihydropyrimidine dehydrogenase deficiency}

Article abstract-Multifocal inflammatory leukoencephalopathy (MIL) is a cerebral demyelinating syndrome that develops after chemotherapy with 5 -fluorouracil (5-FU) and levamisole. The authors report a patient who developed MIL after 5-FU administration not in association with levamisole. She was subsequently diagnosed with partial deficiency of dihydropyrimidine dehydrogenase, an enzyme necessary for 5-FU catabolism. The authors suggest that MIL is a direct result of 5-FU chemotherapy and that patients with dihydropyrimidine dehydrogenase deficiency are at increased risk for this and other toxic effects of 5-FU.

NEUROLOGY 2001;56:110-112

David A. Franco, MD; and Harry S. Greenberg, MD

Multifocal inflammatory leukoencephalopathy (MIL) is a rare syndrome associated with 5-fluorouracil (5FU) and levamisole chemotherapy. The pathogenesis of MIL and the degree to which it may be attributed to 5 -FU or levamisole remain unclear. MIL is reported in patients receiving 5-FU and levamisole in combination or levamisole alone, but not 5-FU alone. We present a patient who developed MIL and, subsequently, a partial dihydropyrimidine dehydrogenase (DPD) deficiency after administration of 5-FU and carboplatin.

Case report. A 65-year-old woman presented in December 1997 with sore throat and dysphagia. A neck CT showed an abnormal soft tissue density in the region of the epiglottis. Subsequent biopsy revealed squamous cell carcinoma of the epiglottis (T3, N1, M0). Chemotherapy was instituted August 6, 1998, with $700 \mathrm{mg} / \mathrm{m}^{2}$ of 5 -FU IV daily for 5 days and a single bolus of $450 \mathrm{mg}$ carboplatin IV. The patient received three cycles, with treatment ending September 21, 1998.

During the first week of September 1998, the patient and her family noted gait and balance difficulties associated with frequent falls. During the third cycle of chemotherapy, her family noted progressive confusion, behavioral change, memory loss, and episodes of intermittent upper extremity paresthesias. Laboratory evaluation showed electrolytes and liver function to be within normal limits. The patient's symptoms improved gradually, returning to normal by mid October 1998. Neurologic examination on October 22, 1998, was normal except for mild gait ataxia, with the patient completing three of five serial seven calculations and recalling two of three objects at 5 minutes.

Brain MRI (figure 1) 3 weeks after chemotherapy discontinuation on October 10, 1998, revealed multiple highsignal lesions on fluid attenuated inversion recovery (FLAIR) and T2-weighted images. On T1-weighted images with gadolinium, there was contrast enhancement in several areas corresponding to T2-weighted abnormalities. A

From the Department of Neurology, University of Michigan Medical Center, Ann Arbor.

Received May 15, 2000. Accepted in final form August 25, 2000.

Address correspondence and reprint requests to Dr. Harry S. Greenberg, Department of Neurology, University of Michigan Medical Center, Taubman Center 1914/0316, Ann Arbor, MI 48109; e-mail: hsgr@umich.edu follow-up MRI (figure 2) on December 16, 1998, showed a mild decrease in the number of enhancing white matter lesions on T1-weighted postcontrast images and a stable appearance of the lesions on T2 and FLAIR images. The patient was clinically unchanged in January 1999.

Testing for DPD deficiency was performed with urine and plasma uracil levels and direct serum enzymatic assay for dihydropyrimidine dehydrogenase. Plasma uracil measured $42.00 \mathrm{ng} / \mathrm{mL}$, and urine uracil measured $44.478 \mathrm{ng} /$ $\mathrm{mL}$. Both values were within the normal range. DPD assay was performed using previously described methods, with peripheral blood mononuclear cells isolated from a $60 \mathrm{~mL}$ whole-blood sample. ${ }^{1}$ Analysis of the frozen $\left(-70{ }^{\circ} \mathrm{C}\right) \mathrm{sam}-$ ple revealed DPD activity to be $0.04500 \mathrm{nmol} / \mathrm{min} / \mathrm{mg}$ protein, indicating a partial enzyme deficiency (table).

Discussion. There have been several case reports of MIL since it was first clearly described in $1992 .{ }^{2}$ This uncommon but increasingly clinically important syndrome is characterized by the gradual onset of multiple neurologic deficits, which can include confusion, ataxia, parasthesias, focal weakness, coma, and death. Symptoms generally develop 6 weeks to 5 months after initiation of combination chemotherapy with levamisole and 5-FU. Brain MRI shows multiple white matter lesions without mass effect. Lesions are hyperintense on T2-weighted imaging and may enhance on T1-weighted imaging after gadolinium administration. ${ }^{3}$ Pathologic tissue examination reveals demyelination with relative axon sparing. ${ }^{2,4}$ Symptoms resolve both with and without therapy, with therapy typically consisting of a short course of corticosteroids. ${ }^{2,5}$

The vast majority of case reports describing MIL are associated with 5-FU and levamisole in combination. ${ }^{3}$ However, a single case occurred after administration of levamisole alone, ${ }^{5}$ and another patient improved after discontinuation of levamisole despite continuation of 5-FU.4 One other report describes multifocal leukoencephalopathy resulting from paclitaxel in two patients who had received 5-FU without levamisole 4 and 11 weeks previously. Paclitaxel frequently produces peripheral and autonomic neuropathies but rarely produces transient encephalopathy and seizures. ${ }^{6}$ Although no direct relationship has 




Figure 1. MRI on October 10, 1998, showing two fluid attenuated inversion recovery images $(A, B)$ with multiple high-signal white matter lesions.

been demonstrated, discussion has focused on levamisole as the most likely causative agent.

Our patient developed MIL resulting from 5-FU administration not in conjunction with levamisole. She received 5-FU in combination with carboplatin, which has not been reported to cause CNS toxicity. Symptoms in our patient developed 4 to 5 weeks after initiation of chemotherapy and were similar, although less severe, than most prior reports of MIL. Our patient experienced more common side effects from 5-FU including mucositis and myelosuppres-

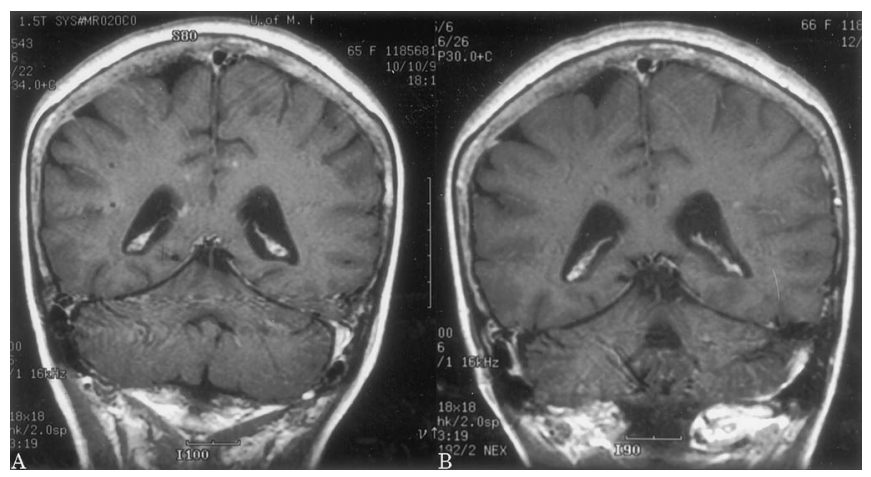

Figure 2. T1-weighted MRI after gadolinium administration with several enhancing lesions on October 10, 1998 (A) and a reduction in the number of enhancing lesions by December 16, 1998 (B). sion, which may also be secondary to systemic 5-FU toxicity, although myelosuppression may also be seen with carboplatin. She did not receive further 5-FU, and her symptoms resolved spontaneously without treatment.

5-FU's role as a causal factor is supported by the presence of partial DPD deficiency, which has not been evaluated in patients with MIL. DPD deficiency is known to place patients at increased risk for severe adverse reactions from 5-FU therapy. ${ }^{7} \mathrm{DPD}$ is responsible for more than $85 \%$ of pyrimidine catabolism, and patients with DPD deficiency may demonstrate increased uracil and thymidine levels in serum and urine. ${ }^{8}$ DPD deficiency is now estimated to occur in $3 \%$ of the adult cancer population and consists of both complete and partial deficiency. Although inheritance is complex, results of familial studies demonstrate an autosomal recessive pattern. Even in complete deficiency states, affected individuals may be asymptomatic prior to pyrimidine administration. ${ }^{9}$

Patients have a partial deficiency if the level of DPD activity falls below the 95th percentile and a complete deficiency if the level is below the 99th percentile or is undetectable. Deficiency can also be measured indirectly by measuring serum and urinary levels of uracil. Results of previous studies have shown that elevated uracil levels may be seen in complete deficiency but may be normal in partial deficiency states. ${ }^{8}$

Neurologic toxicity is a well known, although uncommon, complication of 5-FU and includes pancerebellar dysfunction, peripheral neuropathy, and encephalopathy. Encephalopathy after 5-FU occurs less frequently and is less clearly defined, with clinical features more typical of a diffuse metabolic encephalopathy. It often occurs in the setting of concomitant metabolic abnormalities, and cranial imaging may be normal. ${ }^{9}$ MIL appears to represent a distinct clinical and radiographic syndrome resulting from 5-FU administration, and it may be that patients with DPD deficiency are at increased risk for this life-threatening complication. The toxic effects are likely caused by 5-FU itself rather than one of its derivatives because DPD deficiency results in a failure of 5-FU catabolism. ${ }^{10}$ Drug interactions with levamisole and possibly other chemotherapeutic

Table Dihydropyrimidine dehydrogenase (DPD) activity in peripheral blood mononuclear (PBM) cells and uracil levels in plasma and urine

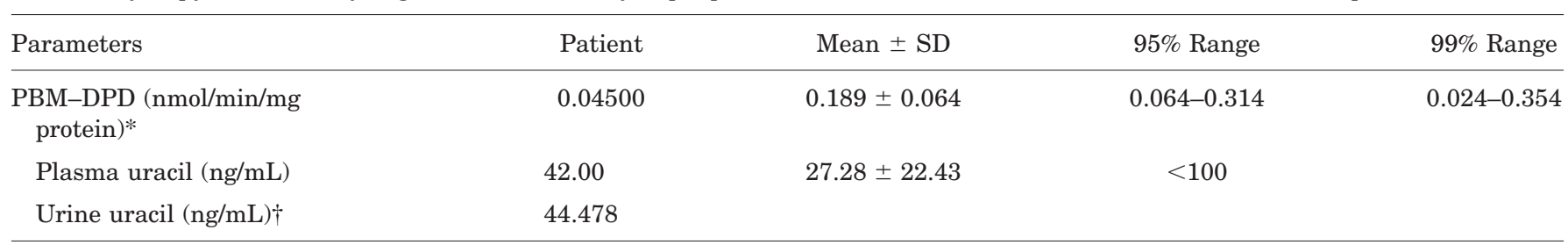

* Mean, 95th, and 99th percentiles for DPD in PBM cells based on frozen samples.

$\dagger$ No established reference ranges for the normal population. 
agents may play an important yet undefined role in the pathogenesis of this syndrome.

\section{References}

1. Lu Z, Zhang R, Diasio RB. Dihydropyrimidine dehydrogenase activity in human peripheral blood mononuclear cells and liver: population characteristics, newly identified deficient patients, and clinical implication in 5-fluorouracil chemotherapy. Cancer Res 1993;53:5433-5438.

2. Hook CC, Kimmel DW, Kvols LK, et al. Multifocal inflammatory leukoencephalopathy with 5-fluorouracil and levamisole. Ann Neurol 1992;31:262-267.

3. Posner JB. Neurotoxicity of 5-fluorouracil and levamisole. Neurology Network Commentary 1997;1:239-243.

4. Chen TC, Hinton DR, Leichman L, Atkinson RD, Apuzzo MLJ, Couldwell WT. Multifocal inflammatory leukoencephalopathy associated with levamisole and 5-fluorouracil: case report. Neurosurgery 1994;35:1138-1142.
5. Kimmel DW, Wijdicks EFM, Rodriguez M. Multifocal inflammatory leukoencephalopathy associated with levamisole therapy. Neurology 1995;45:374-376.

6. Perry JR, Warner E. Transient encephalopathy after paclitaxel (Taxol) infusion. Neurology 1996;46:1596-1599.

7. Diasio RB, Deavers TL, Carpenter JT. Familial deficiency of dihydropyrimidine dehydrogenase. J Clin Invest 1988;81: 47-51.

8. Hayashi K, Kidouchi K, Sumi S, et al. Possible prediction of adverse reactions to pyrimidine chemotherapy from urinary pyrimidine levels and a case of asymptomatic adult dihydropyrimidinuria. Clin Cancer Res 1996;2:1937-1941.

9. Takimoto $\mathrm{CH}, \mathrm{Lu} \mathrm{Z}$, Zhang R, et al. Severe neurotoxicity following 5-fluorouracil-based chemotherapy in a patient with dihydropyrimidine dehydrogenase deficiency. Clin Cancer Res 1996;2:477-481.

10. Aoki N. Reversible leukoencephalopathy caused by 5 -fluorouracil derivatives, presenting as akinetic mutism. Surg Neurol 1986; 25:279-282.

\begin{abstract}
Clinical and spectroscopic improvement in HIVassociated cognitive impairment

Article abstract-To assess the impact of highly active antiretroviral therapy (HAART) on AIDS-associated cognitive impairment, 22 patients with AIDS with $(\mathrm{n}=11)$ and without $(\mathrm{n}=11)$ cognitive deficit were evaluated clinically and by MRS every 3 months for 9 months. Nineteen patients were on HAART at study entry, 21 after 2 months. Cognitively impaired patients presented with a subcorticofrontal deficit and decreased $N$-acetyl-aspartate in frontal white matter. These clinical and metabolic abnormalities reversed partially on HAART, whereas they remained within normal limits in cognitively unimpaired patients.
\end{abstract}

NEUROLOGY 2001;56:112-115

\section{B. Stankoff, MD*; A. Tourbah, MD, PhD*; S. Suarez, PhD; E. Turell, MD; J.L. Stievenart, MD; C. Payan, MD, PhD; A. Coutellier, MD; S. Herson, MD; L. Baril, MD; F. Bricaire, MD; V. Calvez, MD, PhD; E.A. Cabanis, MD; L. Lacomblez, MD, PhD; and C. Lubetzki, MD, PhD}

Whether highly active antiretroviral therapy (HAART) treats or prevents AIDS-associated cognitive impairment is a critically important issue in neuro-AIDS. Since HAART was first widely used, a major decline in the incidence of this complication has been reported. ${ }^{1}$ Few studies, however, have analyzed the impact of HAART on cerebral dysfunction. ${ }^{2-4}$

\footnotetext{
*These authors contributed equally to the work.

From the Fédération de Neurologie I (Drs. Stankoff, Tourbah, Turell, and Lubetzki), Laboratoire de Neuropathologie R. Escourolle (Dr. Suarez), Fédération de Neurologie Mazarin II (Dr. Lacomblez), and Service de Pharmacologie (Drs. Payan and Lacomblez,), Service de Médecine Interne (Drs. Coutellier and Herson); Service des Maladies Infectieuses (Drs. Baril and Bricaire), Laboratoire de Virologie CERVI (Dr. Calvez), Hôpital Pitié Salpêtrière, AP-HP and University Paris VI; and Service de Neuroradiologie (Drs. Tourbah, Stievenart, and Cabanis), Centre Hospitalier National des Quinze-Vingts, Paris, France.

Supported by a grant from ANRS (Agence Nationale de Recherche sur le SIDA) and DRC-APHP (Délégation à la Recherche Clinique-Assistance Publique des Hôpitaux de Paris).

Presented in part at the 51st annual meeting of the American Academy of Neurology; Toronto, Ontario, Canada; April 1999.

Received March 6, 2000. Accepted in final form August 24, 2000

Address correspondence and reprint requests to Prof. C. Lubetzki, Fédération de Neurologie, Hôpital de la Salpêtrière, 47 Bld de l'Hôpital, 75651 Paris Cedex 13, France; e-mail: catherine.lubetzki@psl.ap-hop-paris.fr
}

Methods. We prospectively studied 22 AIDS patients (20 men and two women) without previous or ongoing neurologic disease, major psychiatric disorder, or current alcohol or drug addiction. All had a CD4 cell count below $200 / \mathrm{mm}^{3}$ at study entry or at anytime during the preceding year. The study was approved by the ethical committee of our institution and all patients provided informed consent prior to enrollment.

Using Diagnostic and Statistical Manual of Mental Disorders, 4th ed. (DSM-IV) criteria for AIDS dementia, 11 patients were classified as cognitively unimpaired (CU), and 11 as cognitively impaired (CI). Of the latter, nine had a mild cognitive impairment and two were demented.

Neuropsychological and MRS evaluations were performed at study entry (M0), then every 3 months (M3, M6, and M9) for 9 months. CD4 cell count and plasma HIV-1 RNA level were obtained at M0, then when requested by the treating physician.

The neuropsychological battery, already described, ${ }^{5,6}$ comprised the Mini-Mental State Examination (MMSE), Mattis Dementia Rating Scale, Trail Making A and B, Purdue Pegboard, and Grober and Buschke tests. Depression was evaluated with Montgomery and Asberg Depression Rating Scale (MADRS). 


\section{Neurology}

\section{5-FU multifocal inflammatory leukoencephalopathy and dihydropyrimidine dehydrogenase deficiency \\ David A. Franco and Harry S. Greenberg \\ Neurology 2001;56;110-112 \\ DOI 10.1212/WNL.56.1.110}

\section{This information is current as of January 9, 2001}

\section{Updated Information \& Services}

References

Citations

Subspecialty Collections

Permissions \& Licensing

Reprints including high resolution figures, can be found at: http://n.neurology.org/content/56/1/110.full

This article cites 9 articles, 5 of which you can access for free at: http://n.neurology.org/content/56/1/110.full\#ref-list-1

This article has been cited by 2 HighWire-hosted articles: http://n.neurology.org/content/56/1/110.full\#\#otherarticles

This article, along with others on similar topics, appears in the following collection(s):

Acute disseminated encephalomyelitis

http://n.neurology.org/cgi/collection/acute_disseminated_encephalomy elitis

All Immunology

http://n.neurology.org/cgi/collection/all_immunology

All Oncology

http://n.neurology.org/cgi/collection/all_oncology

Chemotherapy-tumor

http://n.neurology.org/cgi/collection/chemotherapytumor

Information about reproducing this article in parts (figures,tables) or in its entirety can be found online at:

http://www.neurology.org/about/about_the_journal\#permissions

Information about ordering reprints can be found online:

http://n.neurology.org/subscribers/advertise

Neurology ${ }^{\circledR}$ is the official journal of the American Academy of Neurology. Published continuously since 1951, it is now a weekly with 48 issues per year. Copyright . All rights reserved. Print ISSN: 0028-3878. Online ISSN: 1526-632X.

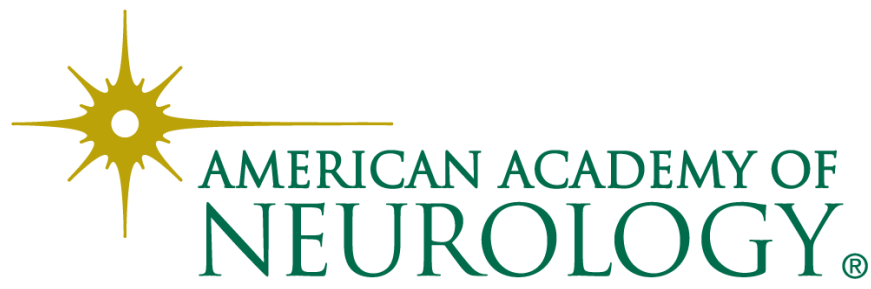

